\title{
CHILE EN EL PRIMER CENTENARIO DE LA INDEPENDENCIA EN 1910: IDENTIDAD Y CRISIS MORAL ${ }^{*}$
}

\author{
Gerson G. Ledezma Meneses ${ }^{* *}$
}

\section{Resumen}

Tratamos aquí del discurso de intelectuales chilenos que levantaron sus voces contra el hispanismo, para acusar a la elite españolizada de corrupción, envuelta en una grave crisis moral cuando conmemoró cien años de Independencia, en 1910. Intelectuales que hasta el momento no han tenido relevancia en la historiografía latinoamericana. Mostramos que mientras, a nivel del continente, se habla de identidad latinoamericana relacionada con lo hispánico, estos escritores identifican el continente desde una perspectiva nacionalista y no americanista. No apenas intelectuales de clase alta y media rescatan el nacionalismo para identificarse como chilenos, también lo hacen críticos socialistas y obreros, intentando defender el país de los inmigrantes y de la imitación europea. Mientras Chile vive un momento especial en las relaciones internacionales con los países de América, estos hombres de letras niegan las ventajas de ese tipo de política externa.

Palabras clave: Primer Centenario de la Independencia, Chile, identidad.

\footnotetext{
* Artículo de Investigación Científica tipo 2: de reflexión, según clasificación de Colciencias.

** Profesor de Historia de América, Departamento de Historia de la Universidad Federal del Ceará, Fortaleza, Brasil.
} 


\begin{abstract}
We analyzed intellectuals chileans speakers who raised their voices against the hispanism, for to accuse corruption the elite hispanicized, living an serious moral crisis when it commemorated centenary of Independence, in 1910. Intellectuals who until the moment not have been relevance in the historiography in Latinamerican. We showed that while, at level of the continent, it speaks of the identity of Latinamerican in related to the Hispanic, this writers identify the continent from a perspective nationalistic and not american. Not only intellectuals of high and medium class rescue the nationalism to identify itself like Chileans, also is make for intellectuals socialist and worker people, trying to defend the country of the imigrantes and european imitation. While Chile lives in a special moment into relations whit countries of America, these intellectuals deny the advantages of this type of external policy.
\end{abstract}

Key words: First Centenary of Independence, Chile, identity

\title{
Introducción
}

Durante la segunda mitad del siglo XIX se va delineando una nueva identidad del ser latinoamericano relacionada con la cultura francesa, dejando de lado las raíces españolas que se querían borrar una vez comenzado el proceso por la liberación nacional, y después de 1862-1864 cuando España intentó volver por lo que, según ella, le pertenecía: sus ex colonias. ${ }^{1}$ Es a partir de mediados del siglo decimonónico que se establece una fuerte lucha

\footnotetext{
${ }^{1}$ Heredia, Edmundo. El imperio del guano. América Latina ante la guerra de España en el Pacífico, Córdoba (Argentina), Alción Editora, 1998.
} 
entre civilización y barbarie, con la intención de mostrar que "en América, todo lo que no es europeo es bárbaro", según palabras de Alberdi, ${ }^{2}$ admirador del pensamiento de Domingo Faustino Sarmiento y su obra prima: Facundo: civilización y barbarie, publicada en $1845 .^{3}$ Sin embargo a medida que la hegemonía norteamericana gana fuerza frente a los países latinoamericanos, intelectuales y políticos comienzan a repensar la identidad del continente, asociándolo a lo hispánico e intentando valorizar lo ibérico, a través de lo mestizo y un sentimiento americanista. Las primeras voces provienen de Cuba, José Martí discursa, no a favor del hispanismo y sí contra el discurso positivista y cientificista de Sarmiento y otros ideólogos latinoamericanos. ${ }^{4}$ Jorge Larraín Ibáñez afirma que:

Una cierta forma de hispanismo gana fuerza a comienzos del siglo $\mathrm{XX}$ con los trabajos de Rodo, Blanco Fombona, Vasconcelos y otros autores que tratan de oponer la raza latina a la raza sajona y que luchan contra el imperialismo norteamericano. Vasconcelos, por ejemplo, argumentaba que 'nosotros no seremos grandes mientras el español de la América no se sienta tan español como los hijos de España. ${ }^{5}$

En contraposición, los indigenistas defendían las raíces autóctonas del continente y luchaban por mejores condiciones para los indios; por el rescate de las identidades étnicas; se contraponen a los hispanistas e intentan realzar los valores y costumbres indígenas en oposición al legado cultural europeo. Ellos querían cambiar la prevalente visión negativa de

\footnotetext{
${ }^{2}$ Citado por Zea, Leopoldo. América Latina: largo viaje hacia si misma, Caracas, Universidad Central de Venezuela, 1983, p. 18.

${ }^{3}$ Sarmiento, Domingo Faustino. Facundo, Buenos Aires, Centro Editor de América Latina \& Biblioteca Argentina Fundamental, 1979.

${ }^{4}$ Martí, José. Nuestra América, Barcelona, Ariel, 1970.

${ }^{5}$ Larraín Ibáñez, Jorge. Modernidad, razón e identidad en América Latina, Santiago, Andrés Bello, 1996, p. 157.
} 
los indios como atrasados y faltos de civilización. ${ }^{6}$ Los discursos indigenistas fueron descalificados y tachados de utópicos; C.I. Degregori, acusa al indigenismo de "exotismo", "pasadismo", "paternalismo" y "populismo". " "En muchos autores el indigenismo tiende a ser más bien ingenuo y romántico en cuanto pinta a las civilizaciones indígenas precolombinas como sociedades idílicas, capaces de constituirse en modelos para el

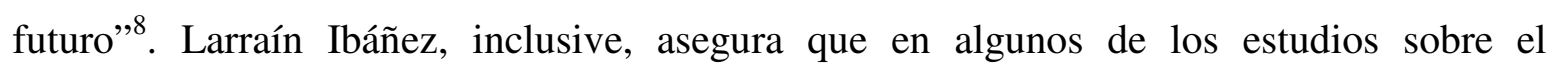
problema indígena presentados en debate en 1992, "se advierte cierta tendencia ingenua a creer que parte de los problemas actuales de América Latina podrían resolverse con una vuelta a los valores y prácticas de esas comunidades indígenas o a los valores religiosos desarrollados en el mestizaje". 9

Estos autores, como Larraín Ibáñez, no han entendido que en muchos de los países de América Latina no predomina ni predominó la "raza ibérica" y sí lo indígena o lo negro; y que si bien ya no se identifican como pueblos autóctonos, es factible que una vuelta a sus costumbres antiguas acabe solucionando los múltiples problemas no resueltos por el hispanismo y mucho menos por la modernidad. No se ha percibido que mientras los intelectuales defendían lo hispánico en América, negaban las demás culturas; ellos eran igualmente culpables como los anglosajones acusados, por ellos, de la masacre de los pueblos indígenas. $\mathrm{Al}$ resaltar lo mestizo estaban automáticamente sepultando las múltiples identidades étnicas existentes en América. Pero en el presente artículo no queremos debatir exactamente esa cuestión.

\footnotetext{
${ }^{6}$ Ibíd, p. 151.

${ }_{8}^{7}$ C.I. Degregori, citado por LARRAÍN IBÁÑEZ, op. Cit., p. 153.

${ }^{8}$ Larraín Ibañez, op. Cit., p. 153.

${ }^{9}$ Ibíd., p. 127.
} 
Es de nuestro interés mostrar que cuando se habla de identidad en América Latina durante las primeras tres décadas del siglo $\mathrm{XX}$, se resalta bastante a los intelectuales hispanistas, tipo Rodó, o a los indigenistas, dejando de lado otros que, como los chilenos, levantaron sus voces contra el hispanismo, para acusar a la elite españolizada de corrupción, envuelta en una grave crisis moral en 1910 cuando orgullosamente conmemoró cien años de Independencia, junto a la Iglesia Católica criticada también. Tratase de intelectuales que hasta el momento no han tenido relevancia en la historiografía latinoamericana. Mostraremos que, mientras intelectuales del continente y chilenos, inclusive, hablan de identidad latinoamericana relacionada con lo hispánico, otros identifican el continente desde una perspectiva nacionalista y no americanista. Veremos que no apenas intelectuales de clase alta y media rescatan el nacionalismo para identificarse como chilenos, también lo hacen intelectuales socialistas y obreros, intentando defender el país de los imigrantes y de la imitación foránea. Sin apelar al indigenismo, algunos de ellos y la prensa de Santiago denunciaron las operaciones de conquista y reducción de los pueblos indígenas al finalizar el siglo XIX y la primera década del XX. Mientras Chile vivía un momento especial en las relaciones internacionales con los países de América, después de un siglo de disputas territoriales, estos hombres de letras niegan las ventajas de esa política externa.

\section{Hispanismo como eje central de la identidad y unión americana}

La fiesta hablada, ${ }^{10}$ en conmemoración del Primer Centenario de la Independencia en Chile, sacó a relucir el hispanismo. Según el senador Vicente Reyes en la Sesión Solemne del

10 Fiesta hablada es una categoría usada por OZOUF, Mona. La fête révolutionnaire, 1789-1799, París, Gallimard, 1976, cuando habla de las fiestas cívicas durante la Revolución Francesa. 
Congreso Nacional el 17 de septiembre de 1910, los chilenos defendieron su independencia gracias a la raza, energía y perseverancia españolas. La independencia había sido política y no había cortado los afectos que habrían de subsistir siempre. España estaba presente en América y en Chile, porque

\footnotetext{
“.....no se vive en vano durante tres siglos a la sombra de un determinado orden de instituciones, sin que ellas echen raíces profundas en el suelo que dominan". ${ }^{11}$
}

Ese hispanismo, además de responder a los anarquistas y al cosmopolitismo, también sería una respuesta a los intelectuales que, como veremos adelante, criticaban la imigración latina y la falta de visión empresarial heredada de los españoles; la identidad hispana se contraponía además a la indianidad peruana y boliviana, los enemigos de Chile en la época del Centenario. Cabe resaltar que esa hispanidad, traducida en la "raça ibérica" y en la cultura latina, unificaba todo el conjunto de ex colonias, en un mismo ritual simbólico de unión americana contra la cultura anglosajona.

El representante de la Cámara de Diputados, José Ramón Gutiérrez, resaltó los esfuerzos conjuntos de los héroes argentinos y chilenos por la independencia del sur, y de los soldados grancolombianos que lucharon por la independencia del Ecuador, Perú y Bolivia en un sentido americano: "la espada de los generales no señala a las legiones los contornos de su país como el escenario de sus proezas. No, porque América es la patria, y sus confines son el límite de la jornada". El senador Salvador Maciá, en nombre del Congreso argentino, declaró que la joven nación chilena estaba dando un alto ejemplo a otras

11 El Mercurio, 18/09/1910. 
naciones al superar todo interés pequeño, toda ambición y rivalidad perturbadora: "hacéis obra grande para vuestra patria, para América, porque enseñáis al mundo que el antes despectivo 'South America', es ya honroso nombre de naciones fuertes, seguras de si mismas, que la dignifican y enaltecen" ${ }^{\prime 2}$. Este discurso, publicado como folleto en la Argentina, fue titulado "El Dogma de la Paz Americana" por los editores que recomendaban su lectura a los hombres de Estado para inspirarlos en los asuntos de política internacional. $^{13}$

Otro discurso impreso como folleto fue el del Ministro de Relaciones Exteriores argentino Carlos Rodríguez Larreta: Chacabuco y Maipo eran símbolos de unión capaces de hacer olvidar querellas mezquinas, "hoy borramos el tiempo y la distancia; confundimos pueblos y gobiernos, regimientos y banderas; pronunciamos juntos los nombres de nuestros mayores que lucharon unidos y reconocemos, en fin, la fraternidad que nos imponen las glorias del pasado". ${ }^{14}$ La invención de la amistad entre argentinos y chilenos buscaba sus raíces en el pasado, y en la historia patria chilena los nombres de O'Higgins y San Martín se entrelazaban: "Mi alma de argentino saludó con efusión (al llegar a Santiago) a San Martín y O'Higgins, los conquistadores de la libertad común, los creadores de naciones nuevas"15. En la sesión solemne del Congreso chileno, el senador boliviano Moisés Ascarrunz discursó en nombre del Congreso de Bolivia, después de oír tantas apologías a la paz y a la fraternidad, demasiado tardías para su país. No demostró resentimiento contra Chile; por el contrario, expresó admiración y respeto al poder militar chileno. Había visto los desfiles

\footnotetext{
12 Ídem.

13 Macia, Salvador. "El Dogma de la Paz Americana", Paraná, Coronado, 1910, 14 pp.

14 Centenario Chileno. Discurso pronunciado por el Ministro de Relaciones Exteriores de la República Argentina Dr. Carlos Rodríguez Larreta en la colocación de la primera piedra del Monumento a la Independencia de Chile, 18 de septiembre de 1910, Santiago de Chile, Imprenta Barcelona, 1910, 8 pp.
} 
militares, "le hemos visto acrecentar su Ejército y Marina, y nos ha exhibido su poder naval en un solemne acto que ha provocado la satisfacción de Inglaterra y del Japón y de Alemania y la admiración de todas las demás naciones". El representante del Congreso boliviano compareció a las fiestas chilenas del Centenario, no apenas para honrarlas, sino también para hacer su manifestación franca y decidida en favor del sentimiento americanista. Chile había ampliado sus fronteras, su riqueza, y su poder en un siglo mientras otros lo habían conseguido en miles de años. Había llegado el tiempo donde a cada día se hacía realidad la idea de convertir América del Sur en una sola entidad, tal como América del Norte: "todos los pueblos que progresan se dirigen en la América del Sur intuitiva y espontáneamente a un fin único; la Unión Americana. La civilización ensancha sus fronteras, rompe las vallas estrechas que la encierran y se universaliza propagándose". ${ }^{16}$

Las propuestas de paz e integración de las elites chilenas encontraron soporte también en el discurso de José Enrique Rodó, autor de Ariel, representando Uruguay. Escritor de varios libros y textos donde rescataba la idiosincrasia hispanoamericana amenazada por el cosmopolitismo, discursó sobre el ideal bolivariano. El pensamiento integracionista de Rodó partía de la historia compartida: origen, lengua, tradiciones, costumbres. Las nuevas generaciones estaban llamadas a construir la nueva patria americana. El Centenario no debería apuntar apenas para los intereses chilenos, él también tenía mucho de americano y, en ese sentido, Rodó privilegiaba lo americano sobre lo chileno, porque se estaba celebrando el Centenario de la Independencia de América Española, "porque en espíritu y

\footnotetext{
${ }^{15}$ Macia, Salvador. "Una impresión de viajero", Buenos Aires, Imprenta La Leonesa, 1910, 15 pp.

${ }^{16}$ El Mercúrio. Santiago de Chile, 18/09/1910.
} 
verdad de la historia, hay una sola revolución hispanoamericana". La revolución se había hecho, no para que quedaran libres un puñado de naciones, donde hoy prevalecía el concepto de patria; la revolución significaba armonía entre pueblos vinculados por la cultura e, inclusive, por la geografía "y por todo cuanto puede servir de fundamento a la unidad de una conciencia colectiva". Hacía un llamado también a la memoria, ella sería la luz que irradiaría la unidad del pueblo americano como testimonio de la historia. Rodó sentía gran satisfacción por la adhesión internacional que el Centenario había provocado: hoy en Chile, ayer e la Argentina, y consiste esa afirmación en decir que esta América Española, tan discutida, tan negada, tan calumniada por la ignorancia y el orgullo ajenos, y aun por el escepticismo de sus propios hijos, empieza a existir para la conciencia universal; empieza a atraer a sí la atención y el interés del mundo.

Pero tal reconocimiento se debía, no al desarrollo cultural, ni a la influencia política en la sociedad de las naciones, sino a las ventajas materiales, riquezas que ahora, de nuevo, Europa codiciaba. Después de la Independencia, el mundo continuó desconociéndonos, decía Rodó; o, intentando mal conocernos, dudando de nosotros mismos, "duda cruel que no perdonó, en el Gehsemaní de Santa Marta, al alma lacerada del Libertador; de esta forma, y dejando atrás las dudas, siendo hasta ayer apenas un pedazo de la geografía empezamos a ser una fuerza. Éramos una promesa temeraria: empezamos a ser una realidad". En el futuro, si a alguien le preguntaran por el nombre de su patria, no debería responder México, Chile, etc., e sí: América. La política que no se orientase por esos propósitos sería vana. Llamó la atención contra la imitación de Europa y sus costumbres; su civilización había contribuido, pero era tiempo de hacer algo nuevo a partir de lo aprendido, dejando de ser colonias espirituales. La unidad y amistad entre las naciones llevarían la 
armonía internacional, "fundada en el acuerdo de los intereses de todos por el respeto leal de los derechos de cada uno". Elogió a Chile; la humanidad, como ser colectivo, no existía aún, pero existiría algún día, digamos nosotros que América, la nuestra, la de nuestra raza, principia a ser, - como persona colectiva consciente de su identidad. Congresos que se reúnen, vías férreas que se tienden de nación a nación, litigios internacionales que se resuelven, vínculos intelectuales que se estrechan: todo concurre a esa manifestación de una plena conciencia americana. ${ }^{17}$

Por su parte el obispo Ramón Ángel Jara, en el lanzamiento de la piedra fundamental del Monumento de la Independencia de Chile, manifestó que se estaban viviendo momentos de fraternidad americana e hizo votos para que rápidamente pudiesen los chilenos ver entrelazada con su propia bandera la única que faltaba en aquel encuentro de confraternidad continental, o sea, la del Perú. ${ }^{18}$ Pero estaba claro que los diplomáticos chilenos no estarían dispuestos a ceder territorios que, según ellos, históricamente eran chilenos.

\section{La crisis moral de la elite chilena del Centenario}

En las proximidades de la conmemoración del Segundo Centenario de la Independencia, intelectuales y críticos intentan aclarar el papel de Chile en este milenio. Tratam de comprender la situación económica del país en los últimos años y se hacen balances sobre la dictadura militar, especialmente la responsabilidad del general Augusto Pinochet. La meta es hacer de Chile un país moderno, pero la preocupación es grande cuando

\footnotetext{
${ }^{17}$ Rodo, José Enrique. El Centenario en Chile. Discurso pronunciado, en representación del Uruguay, en la sesión solemne celebrada por el congreso chileno, durante las fiestas del Centenario, el 17 de Setiembre de 1910, Montevideo, Impresora Uruguaya Colombino S.A., 1975. Este discurso aparece publicado también en El Mercúrio. Santiago de Chile, 18/09/1910.

${ }^{18}$ El Mercúrio. 19/09/1910.
} 
en aras de esa meta la mayoría parece dispuesta a aceptarlo todo: desde la violación de los derechos humanos y la dictadura en la década de los sesenta, pasando por un Santiago contaminado que crece como una mancha informe y viscosa en la década de los ochenta, hasta una política algo insulsa y el olvido del pasado en la década de los noventa". ${ }^{19}$

En 1992 España conmemoró el V Centenario del “descubrimiento de América” en Sevilla con una Exposición Universal. Chile, Venezuela y México presentaron exposiciones en pabellones individuales. Chile exhibió un iceberg de sesenta toneladas. Con el insólito "monumento" se quería confirmar la imagen de un país moderno, dinámico, eficiente, creativo y confiable. Los publicistas contratados por el gobierno chileno se propusieron mostrar a Europa que el país no era exótico; que era básicamente nuevo, sin ninguna tradición precolombina, semejante a las naciones europeas:

al postularlo como un país diferente, se pensó sin duda en el resto de América Latina. Aun cuando todo signo estético es polisémico, en la intencionalidad de los diseñadores el iceberg connota la idea de que somos un país 'frío', no 'cálido', que no se ajusta a los rasgos que caracterizan en la imaginación europea el modo de ser latinoamericano: el tropicalismo, la informalidad y lo premoderno (...) La operación pretendía, entonces, refundar nuestra identidad en la diferencia; diferencia, por una parte con el resto de las naciones latinoamericanas, y por otra, con nuestro propio pasado. ${ }^{20}$

\footnotetext{
${ }^{19}$ Subercaseaux, Bernardo. ¿Chile, un país moderno? Santiago, Ediciones B, 1996, pp. 59-68.

${ }^{20}$ Ídem, pp. 59-68.
} 
Para presentarse como un país moderno, Chile debía aliarse a homólogos económicamente avanzados, estableciendo relaciones con Taiwan o Corea del Sur; esto era más importante que relacionarse con países latinoamericanos. Negar la presencia latina, ligada al tropicalismo y a los andino, significaba borrar también las particularidades étnicas del país, sugerir que no tenía problemas étnicos, omitiendo, por ejemplo, la cultura mapuche.

En la actualidad, con una mujer de izquierda al frente de la presidencia de la República chilena, la sociedad se divide: unos quieren dar continuidad al proceso neoliberal introducido en la década de los 80 por el dictador, que aunque haya violado los derechos humanos, la modernización económica promovida por la dictadura se convierte en un saldo favorable; otros no admiten que modernización justifique injusticia social.

Polémicas análogas ocurrían hace cien años, en la antesala del Primer Centenario de la Independencia de Chile. La sociedad chilena se modernizaba según los esquemas europeos; la clase alta acumulaba grandes lucros en los negocios del salitre, nadando en un cuadro de relaciones internacionales que favorecía el Estado chileno, todo esto en medio a la sordidez de los conventillos y la crisis moral de toda la sociedad. Varios intelectuales y políticos, obedeciendo a diferentes consideraciones, apuntaban que, a pesar de Chile del Centenario estar pasando por un buen momento en la economía, vivía una crisis latente de orden moral, social y también económica. Se preocupaban con la regeneración del país:

todo el oropel de esta riqueza ocultaba el hecho que la mayor o menor producción del abono natural (salitre) como su valor, dependían del valor que fijaran las leyes del mercado internacional, circunstancia que había tenido, sólo apenas dos años atrás del centenario, una repercusión en la estructura económica al presentarse en el país los efectos de la crisis cíclica 
mundial y provocar serios trastornos en la salud económica nacional. Pero estos hechos no inquietaban en mayor grado a los círculos gobernantes imbuidos y confiados como estaban en el restablecimiento del equilibrio económico por obra y gracia de las 'leyes naturales' de la economía capitalista. $^{21}$

La crisis era latente en otros sectores socioeconómicos; se advertía en la degradación del sistema electoral; la degeneración de los operarios, indios y campesinos viciados en el alcohol; la empleomanía y el desempleo; en fin, la crisis se evidenciaba en constantes revueltas populares y huelgas protagonizadas por trabajadores industriales, desempleados, artesanos, trabajadores del salitre e imigrantes de origen campesina en vías de proletarización. $^{22}$

Uno de los críticos del sistema establecido en el país al finalizar el siglo XIX fue Enrique Mac-Iver Rodríguez (1845-1922). Abogado, se inició en la política como miembro del Club de la Reforma en 1868; ingresó en el Partido Radical donde se destacó; fue antibalmacedista durante la guerra civil de 1891 y, después de ella, con su espíritu de conciliación fue el primero en aceptar como legales los actos del Presidente Juan Manuel Balmaceda. ${ }^{23}$ En 1900, en su Discurso sobre la crisis moral de la república, Mac-Iver enfrentó la aristocracia afirmando que Chile vivía no apenas una crisis económica, sino una crisis integral. "Los chilenos no somos felices"; el malestar no se presentaba sólo en una región del país o para un determinado grupo social, sino en todo el territorio nacional. "El presente no es satisfactorio y el porvenir aparece entre sombras que producen

\footnotetext{
${ }^{21}$ Barría Serón, Jorge. "Evolución histórica de Chile de 1910 hasta nuestros días", en Anales de la Universidad de Chile, año CVVIII, $\mathrm{n}^{\circ}$ 120, 1960, pp.50-75.

${ }^{22}$ CÁCERES QUIERO, Gonzalo, DEL ALCÁZAR GARRIDO, Joan et al.. Las primeras democratizaciones en América Latina: Argentina y Chile, 1880-1930, Valencia, Tirant lo Blanch Libros, 1997, p. 140.
} 
intranquilidad". Mac-Iver advirtió que la crisis moral, a pesar de generalizada, se percibía más nítidamente a la sombra de grandes figuras públicas corruptas. La clase dirigente chilena había conseguido grandes desarrollos tecnológicos en el siglo XIX, mas el ritmo de los avances había decaído y la culpa estaba en las grandes cantidades de dividendos dejados por la exportación del salitre:

Que amargo despertar. Sueños fueron puertos y ferrocarriles, canales y caminos, escuelas e inmigración, industrias y riqueza, trabajo y bienestar; el oro vino, pero no como lluvia benéfica que fecundiza la tierra, sino como torrente devastador, que arrancó del alma la energía y la esperanza y arrasó con las virtudes públicas que nos engrandecieron. ${ }^{24}$

Cuando Mac-Iver relacionaba crisis moral y economía salitrera, estaba consciente de que el dinero obtenido en estos negocios había desmoralizado su clase. Esta falsa riqueza había llevado a los empresarios chilenos a consumir sus lucros en la manutención de un modo aristocrático de vida. Justamente por la época del Centenario de la Independencia la meditocracia ${ }^{25}$ cuestionaba esta aristocracia.

Otro autor que también hizo duras críticas a la clase alta chilena en la década del Centenario fue Nicolás Palacios (1854-1911). En Raza Chilena, 1904, señala la crisis enfrentada por la República a comienzos del siglo XX; diferentemente de Mac-Iver, Palacios pertenecía a una familia de agricultores más o menos modesta, según algunos, o aristocrática provinciana, rica sin exceso. Médico, trabajó en las salitreras del norte hasta el final de la vida; bastante marcado por la Guerra del Pacífico, jamás conseguiría olvidarla,

${ }^{23}$ GAZMURIR, Cristian. Testimonios de una crisis, Chile: 1900-1925, Santiago, Universitaria, 1980, p. 14.

24 Mac-Iver, Enrique. Discurso sobre la crisis moral de la República, Santiago de Chile, Moderna, 1900. 
“....siempre había tenido un patriotismo espontáneo, de estilo popular, y siempre amor, igualmente instintivo, por las glorias nacionales, la historia de Chile y el Ejército; estos sentimientos se le volvieron, con la guerra, indelebles. Desde otro ángulo, ella también lo hizo amar al hombre de pueblo -el 'roto"'. ${ }^{26}$

Su obra destaca el problema racial. Según Palacios, los chilenos eran una raza mestiza, pura en las dos raíces, la materna indígena y la paterna ibérica, constituída de españoles selectos, rubios, belicosos y conquistadores. De la unión entre esa raza blanca, "gótica", y la raza mapuche también belicosa y patriarcal, se formó una raza poderosa que marcaría el destino de Chile. Palacios resaltaba el vigor del mestizo chileno que las elites despreciaban y explotaban. El Roto $^{27}$ debería ser protegido contra los imigrantes del Viejo Continente, especialmente los latinos, y contra el alcohol, que juntos amenazaban abastardar y destruir la raza $^{28}$. Palacios veía en la imigración el origen de vicios ideológicos y morales que debilitaban la raza mestiza chilena vigorosa, apta para la guerra. Más duramente que las ideas socialistas y anarquistas que rechazaba, Palacios denunciaba la actitud de desprecio de la aristocracia por el Roto, la inmoralidad de la clase alta: "juntos han venido a nuestra patria la depresión de la idea de justicia, el descenso de su nivel moral, el apocamiento de los caracteres, la desorganización administrativa y la preferencia por los países latinos del

\footnotetext{
${ }^{25}$ Clase Media.

${ }^{26}$ Vial Correa, Gonzalo. Historia de Chile (1891-1973). Vol. I, La sociedad chilena en el cambio de siglo (1891-1920), Santiago de Chile, Santillana, 1981, pp. 918-919.

${ }^{27}$ El Roto era el campesino, el operario, el morador de los conventillos. La expresión fue consagrada en la novela El Roto de Bello, Joaquin Edwars (1920), que retrata la Santiago de principios del siglo XX. La obra es una dura crítica a la opulencia de la clase alta y al desperdicio en las mansiones que contrastan con la Santiago pestilente donde nació Esmeraldo, el protagonista.

${ }^{28}$ Palacios, Nicolás. Raza Chilena, tomo I. Santiago de Chile, Chilena, 1918, pp. 40-41.
} 
viejo mundo". ${ }^{29} \mathrm{Al}$ final de la vida, Palacios, arruinado, vivía en un hotel en Iquique. El 21 de diciembre de 1907, a camino de la Escuela Santa María, presenció el sangriento fusilamiento de los trabajadores en huelga, experiencia que amargó el resto de sus días. Una bandera chilena estaba entre sus últimos bienes, cabía en una valija; sus amigos tenían instrucciones para amortajarlo con ella.

Lo más profundo y original en Nicolás Palacios fue su amor hacia el pueblo, hacia el roto. Una sociedad -clase alta y clase media- máximamente europeizada y que adoraba todo lo foráneo; un emigrante prepotente en razón de ese mismo servilismo universal; una intelectualidad extranjerizada, había olvidado quién era el auténtico protagonista de nuestra historia; y aun lo vilipendiaban. $^{30}$

Otro intelectual de clase media que también protestó frente a la crisis moral de la clase alta del Centenario fue Tancredo Pinochet Le Brun, autor de La Conquista de Chile en el siglo XX (1909). Como Palacios, acusó al sistema socioeconómico de entregar el país a intereses extranjeros y culpó a las ideologías foráneas por la pérdida del sentimiento nacional; el socialismo y el anarquismo habrían llevado a la pérdida del patriotismo y a la decadencia del civismo chileno ${ }^{31}$. Como la elite cedía el país a los intereses extranjeros, convocaba al pueblo chileno a llenarse de egoísmo nacional como las naciones bien constituidas: "el hecho es que despreciamos nuestra raza y nosotros los chilenos estamos como que fuera de

\footnotetext{
${ }^{29}$ Ídem, p. 330.

${ }^{30}$ Vial Correa, Gonzalo, op. cit., p. 923.

${ }^{31}$ Pinochet Le Brun, Tancredo. La Conquista de Chile en el siglo XX, Santiago de Chile, La Ilustración, 1909, p. 10-11.
} 
nuestra Patria, admitidos por favor en nuestra tierra" ${ }^{32}$. La crítica de Pinochet Le Brun también recayó sobre el carácter noble e hidalgo heredado de los españoles por las elites chilenas que no se interesaban por actividades técnicas e industriales. El problema era ancestral, venía de aquella "España noble, ociosa y espiritual y la España villana, estúpida y laboriosa. De ahí nació el desprecio al trabajo y el menosprecio al trabajador" ${ }^{33}$.

Justamente en el año del Centenario, Alejandro Venegas Carus, bajo el seudónimo de Julio Valdés Cange, redactó Sinceridad, Chile íntimo en 1910, la más dura crítica contra la clase dominante de la belle époque. Hasta hoy la obra provoca polémica; hay quien afirme que Sinceridad fue escrita por

un hombre deprimido hasta los límites de la anormalidad... o quizás más allá. Pero ese desquiciamiento, ese indudable trastorno no tuvieron únicamente un origen psíquico. Derivaron también -y más que nada, es probable- de los hondos males advertidos por el doctor en el cuerpo patrio y de la impotencia personal para remediarlos ${ }^{34}$.

Apelando a la juventud aún no contaminada por la elite que habían perdido hacía mucho tiempo la esperanza de la patria, Venegas denunció la falsa riqueza en que se sustentaba aquella clase alta, creyendo en prosperidad donde apenas había quiebra; la elite vivía una sorprendente crisis moral, pero aparentaba lo contrario;

\footnotetext{
32 Ídem, p. 65.

${ }^{33}$ Ibidem, p. 148.

${ }^{34}$ Vial Correa, Gonzalo, op. cit., p. 224.
} 
"así los que rijen los destinos de nuestra patria rasguñaron el fondo de las arcas fiscales para vestirla rejiamente i representar la farsa de la opulencia" ${ }^{35}$.

Sinceridad se presenta como una serie de cartas enviadas por Venegas al recién electo presidente Ramón Barros Luco. En la primera carta asegura que el origen de la crisis moral de la elite se aprofundó después de la Guerra del Pacífico, cuando la aristocracia pasó a gobernar para si misma, desconociendo la gran mayoría. Apuntó más específicamente las consecuencias de la emisión de papel moneda inconvertible desde 1878. El ex presidente Pedro Montt, había sido incapaz de dominar los "grandes delincuentes". La regeneración del país vendría de lo alto, pues el pueblo

\footnotetext{
...."es ignorantísimo i hasta ahora ha sufrido las espoliaciones e iniquidades con la tranquilidad pasiva de una bestia de carga; no podemos esperar, pues, su rejeneracion del ejercicio consciente de sus derechos"
}

El régimen monetario y el ordem económico habían provocado una gran crisis en la agricultura. Sin una moneda de valor fijo y un gobierno de hombres honrados garantizando su estabilidad, dificilmente los capitales extranjeiros retornarían a Chile. La crisis afectaba directamente a los trabajadores desempleados o con baja renta; una veintena de industrias ficticias vivía de la contribución indirecta paga por los consumidores ${ }^{37}$. Después de mostrar el empobrecimiento paulatino del país, el libro trata la decadencia y corrupción de los partidos políticos, de los males en la administración de justicia y en los servicios

\footnotetext{
${ }^{35}$ Valdés Cange, Julio. Sinceridad, Chile Íntimo en 1910, Santiago, Universitaria, 1910, pp. XI-XVII.

${ }^{36}$ Ídem, pp. 10-11.
} 
gubernamentales, profundamente desmoralizados como consecuencia del sistema monetario.

Las cartas 7 a 11 tratan con profundidad los problemas de la educación. En las universidades, los profesores eran anticuados. Los Institutos Comerciales no daban educación de calidad; la enseñanza agrícola y minera era pésima; la enseñanza dada por las monjas era un engaño,

una de las manifestaciones mas trascendentales de nuestra pésima administración pública, es la desorganización de la enseñanza del estado en todas sus categorías, i la licencia escandalosa de los particulares para especular con la educación de la juventud, engañando a los padres de familia, sobre todo cuando tiene sobre ellos el ascendiente relijioso ${ }^{38}$.

En la organización militar, faltaba cultura científica y moral; los reclutas sufrían castigos inhumanos que llevaban a algunos al suicidio. Los cuarteles se comparaban a los conventos, allí imperaba la rigidez, la austeridad aparente, el espíritu del cuerpo, las intrigas y rivalidades. La obra criticaba en seguida a la Armada que, en lugar de dedicarse a las causas nobles del país, buscaba apenas lo superficial, las apariencias. Para el Centenario, las ciudades estaban cubriéndose de mármol, con casas que aspiraban a ser palacios y mansiones, al lado de pestilentes pocilgas, verdaderos tugurios donde reinaba la pobreza y la estrechez:

\footnotetext{
${ }^{37}$ Ibidem, p. 32.

38 Ibidem, p. 140.
} 
Santiago misma, por mas que ha gastado mas de lo que tenía en afeites i se ha echado encima el concho del baúl para recibir dignamente el Centenario, no ha podido ocultar sus calles mal pavimentadas i cubiertas de polvo, sus acequias pestilentes, sus horrorosos conventillos que en vano trata de disfrazar con el nombre modernísimo de cité, sus interminables i desaseados barrios pobres, i en fin sus aspecto de aldea grande i sencillota ${ }^{39}$.

Venegas abordó también la conquista de la Araucanía, sometida a sangre y fuego por el ejército nacional en 1881:

nuestros guerreros, venciendo a los mapuches, se apoderaron de sus mejores tierras i espulsaron a sus antiguos ocupantes; luego se organizó la administracion i los encargados de ella continuaron el despojo de una manera inícua; en seguida acudieron multitud de colonizadores, en su inmensa mayoría aventureros de la peor especie, que fueron a completar la obra de depredacion i de pillaje ${ }^{40}$.

Después de la alusión al problema indígena, Venegas focalizó la grave situación de los obreros del salitre. La asistencia pública en Iquique se reducía a un único hospital para miles de operarios. Las escuelas, en pésimo estado, funcionaban en espacios inadecuados y sin condiciones higiénicas. En la Escuela Santa María de Iquique, era triste "ver 300 muchachos (...) amontonados en aquel horroroso edificio que aun conserva intactos los huecos que abrieron las granadas en sus paredes en el día mas triste de la pasada administración"

\footnotetext{
39 Ibidem, p. 161.

${ }^{40}$ Ibidem, p. 171.

${ }^{41}$ Ibidem, p. 190.
} 
Nada se podía esperar de los partidos políticos, cuyas promesas quedaban apenas en el papel. Tampoco de la Iglesia, que hacía 19 siglos mantenía al pueblo

\footnotetext{
"bajo su éjida i no hizo otra cosa que esplotarlo, predicándole resignacion, i solo ahora, cuando se le escapa de las manos, viene a preocuparse de remediar sus desgracias"42.
}

La prensa, que en otros países al menos ventilaba los problemas sociales, en Chile era "una cortesana vil que prodiga a la aristocracia sus interesadas lisonjas, alagando sus vanidades i encubriendo sus vicios (...) i talvez a él [o jornalismo] mas que a nadie, debemos la delincuencia desembozada de los de arriba i la ceguedad lastimosa de los de abajo" ${ }^{43}$.

El triunfo en la guerra del Pacífico había llevado a las elites a creer en el destino del país como una gran potencia militar, descuidando los problemas sociales y el progreso económico. Chile debería, tal como los Estados Unidos, preocuparse primero por el progreso económico y después por la formación de la potencia militar. Debería educar al pueblo, hacerlo valiente, fuerte, con mejor calidad de vida, con virtud. Venegas veía en la reforma del sistema electoral y del orden político en general la solución a los múltiples problemas económicos, políticos y sociales. El sufragio universal debería extenderse a todos los ciudadanos, incluidas las mujeres. Era urgente eliminar la ostentación y priorizar los problemas más representativos, atraer capitales extranjeros abundantes y baratos. Era urgente la reforma administrativa, contratar funcionarios competentes y honrados, pagando salarios equitativos. En las regiones apartadas como Tarapacá y Antofagasta, urgía colocar

\footnotetext{
${ }^{42}$ Ibidem, p. 211.

${ }^{43}$ Ibidem, pp. 212-216.
} 
en la administración personal patriota capaz de chilenizarlas ${ }^{44}$. Después de las denuncias, Venegas sugirió reformas en la educación, en el Ejército y en la Armada, enfatizando la importancia de la cultura y del nacionalismo, una nueva legislación laboral y la separación entre la Iglesia y el Estado. Finalmente llamó la atención para otros puntos que consideraba capitales: la degeneración de la raza por el alcoholismo, enfermedades venéreas y casamientos entre parientes consanguíneos.

Profesor del Liceo de Talca, Venegas fue perseguido por la publicación del libro, siendo forzado a jubilarse en 1915. Tal como otros críticos de la época del Centenario, Venegas también consideró que la principal crisis era de orden moral. La solución estaría en la regeneración de las elites. Chile presentaba, por lo tanto, una crisis de identidad. Las elites dirigentes, buscando un cosmopolitismo que las identificara culturalmente con Europa, enfrentaban la crítica de reformadores nacionalistas que privilegiaban el orden moral. Se trataba de tensiones entre la dimensión material y espiritual del progreso; entre el nacionalismo y el cosmopolitismo; entre la conciencia estética y la conciencia pragmáticoiluminista; entre lo rural que pierde paulatinamente significación y las ciudades que se convierten en polo de religación del continente; entre el reclamo por una cultura propia y la inserción en un sistema internacional que exige la participación en la cultura contemporánea de occidente ${ }^{45}$.

Venegas, decepcionado con el sistema imperante, confiaba en que las soluciones por él sugeridas mostrarían el camino a seguir durante el siglo XX. Su discurso no era

\footnotetext{
${ }^{44}$ Ibidem, pp. 279-283.

${ }^{45}$ Subercaseaux, Bernardo. Historia de las ideas y de la cultura en Chile, Tomo II. Santiago de Chile, Universitaria, 1997, p. 215.
} 
improvisado o sin fundamento: conocía el país viajando a pie, a caballo, en la tercera clase del tren y del navío, gastando en esto su modesta renta ${ }^{46}$.

El clima de fiesta, en la conmemoración del Centenario de la Independencia, estuvo amenazado también por el discurso crítico de un líder socialista muy conocido, afiliado al Partido Demócrata en 1894: Luis Emilio Recabarren Serrano. Trabajó desde su niñez en los talleres tipográficos de varios periódicos, militó en la prensa socialista llegando a la dirección del semanario La Democracia, en 1901. En 1906, la mayoría de la Cámara de Diputados descalificó los votos que obtuviera como candidato por Antofagasta. Acusado de agitación contra el Estado y condenado a 541 días de prisión, huyó y se exilió por un año en Argentina. Se hizo miembro del Partido Socialista, recorrió varios países de Europa y retornó a Chile donde cumplió su pena de prisión entre noviembre de 1908 y agosto de 1909. Antes, viajó por todo el territorio chileno dando conferencias a los trabajadores y organizando el Partido Socialista. Pasó el año del Centenario en Santiago desarrollando una incesante militancia cultural de esclarecimiento ideológico, histórico y político. Publicó el folleto El sembrador de odios; en su conferencia sobre el Centenario titulada Ricos y pobres a través de un siglo de vida republicana analizó el carácter clasista del movimiento emancipador a partir de 1810; el enfrentamiento entre capitalistas y trabajadores del salitre, de las artesanías y del comercio; destacó el papel del pueblo en las luchas revolucionarias

\footnotetext{
${ }^{46}$ Vial Correa, Gonzalo, op. cit., p. 224.
} 
contra España, criticando la historiografía que privilegiaba a los líderes de la clase alta en detrimento de otros héroes ${ }^{47}$.

Como Enrique Mac-Iver y Alejandro Venegas, Recabarren también comienza por la crítica a la decadencia moral de la burguesia y de la aristocracia desde la Guerra del Pacífico (1879) y de la anexión de la región salitrera: “el progreso económico que ha conquistado la clase capitalista ha sido el medio más eficaz para su progreso social, no así para su perfección moral (...) nuestra burguesía se ha alejado de la perfección moral verdadera”. La crisis moral no afectaba sólo a los sectores altos de la sociedad chilena, mas también a lo operarios, peones y campesinos que estaban en situación equivalente a aquella de 1810. La desmoralización se daba más en la ciudad que en el campo, y esto en un ambiente que nunca saldría de la tutela moral del catolicismo, afirmaba. Las prisiones eran escuelas donde los criminales y no criminales perfeccionaban sus vicios solitarios y se habituaban a la inversión sexual. La crisis moral afectaba toda la sociedad. La vida en los conventillos y los suburbios era la escuela primaria de los vicios y de los crímenes: "y si a los cien años de vida republicana, democrática y progresista, como se le quiere llamar, existen estos antros de degeneración, cómo se pretende asociar al pueblo a los regocijos del primer centenario?” Contra la perspectiva de Alejandro Venegas, Recabarren esperaba que la solución de los problemas no vendría de los dueños del poder "sino por la acción proletaria que empuja la acción de la sociedad" 48 .

La clase media había progresado un poco, pero, esclava de la vanidad, aspiraba grandezas superfluas y brillo falso. Los comerciantes se caracterizaban por el fraude, explotando

\footnotetext{
${ }^{47}$ Jobet, Julio César, Barría, Jorge et al.. Obras Selectas de Luis Emilio Recabarren, Santiago de Chile, Quimantú, 1971, p. 23.
} 
inhumanamente a los más pobres. Todas las denuncias se concentraron en la crítica a la conmemoración:

Y esto también llamaremos progreso? Esto que ha progresado tanto en el transcurso de los últimos cien años, también es digno de asociarle al entusiasmo de las festividades centenarias? (...) Celebrar la emancipación política del pueblo! Yo considero un sarcasmo esta expresión. Es quizás una burla irónica (...) creemos necesario indicar al pueblo el verdadero significado de esta fecha, que en nuestro concepto sólo tienen razón de conmemorarla los burgueses, porque ellos, sublevados en 1810 contra la corona de España, conquistaron esta patria para gozarla ellos y para aprovecharse de todas las ventajas que la independencia les proporcionaba; pero al pueblo, la clase trabajadora, que siempre ha vivido en la miseria, nada, pero absolutamente nada, gana ni ha ganado con la independencia de este suelo de la dominación española ${ }^{49}$.

Al contrario de Argentina en su Centenario, donde las elites y gran parte de la intelectualidad sólo tenían vistas para el progreso del país, Chile experimentó un amplio debate sobre su verdadera situación. En este debate, la gran prensa también desempeñó un papel importante. En medio de la conmemoración, El Diario Ilustrado enfatizó la decadencia de la minería de oro y plata e, inclusive, de cobre; a pesar de grandes avances en la educación, 60\% de la población aún era analfabeta. La medicina, la salud, el saneamiento básico eran deficientes; igualmente con un Instituto de Higiene moderno en Santiago, la varíola, el tifo y otras enfermedades eran casi endémicas y, sumándose a otras como la tuberculosis, hacían con que sólo $26 \%$ de los chilenos llegaran a los 70 años. El

\footnotetext{
${ }^{48}$ Ídem, pp. 246- 255.

${ }^{49}$ Ibidem, p. 262.
} 
alcoholismo continuaba creciendo, tomando por lo menos la tercera parte del tiempo de los trabajadores $^{50}$. Un año antes de la fiesta del Centenario, El Ferrocarril denunció la usurpación de las tierras de los indígenas por parte de terratenientes y otras personas inescrupulosas y la omisión del gobierno ${ }^{51}$.

Francisco Antonio Encina Armanet, en Nuestra Inferioridad Económica, publicado en 1911, enfatizó la prioridad de la crisis económica, pues la crisis moral estaría instalada desde los tiempos coloniales. El problema era un grave declinio económico. Hasta mediados del siglo XIX el comercio había permanecido en manos de nacionales con gran participación de los chilenos en comercio exterior; el comercio se extendía más allá de las fronteras; ahora, los comerciantes extranjeros habían sofocado la iniciativa comercial en el exterior, tal como en las industrias de salitre y cobre. La causa de la inferioridad económica se encontraba en la falta de sentimiento nacional. "El deseo de ser grandes, la voluntad de dominar y absorber los elementos extraños que se ponen en contacto con nosotros están dormidos" $^{52}$. Según Encina, los intelectuales habían dado a conocer la crisis moral de las elites porque a partir de 1891 las clases medias y otros sectores que habían luchado por la causa del Parlamento se sintieron traicionados, ya que las elecciones libres y la autonomía de los partidos no se concretizaron. De 1885 a 1900, hubo un alto grado de pesimismo. Movidos entonces por la creencia en la eficacia intrínseca de las formas de gobierno, constituciones y leyes, $70 \%$ de los chilenos habían esperado que tales panaceas levantarían

\footnotetext{
${ }^{50}$ El Diario Ilustrado, Santiago, 18/09/1910.

${ }^{51}$ El Ferrocarril, Santiago de Chile, 07/11/1909.

${ }^{52}$ Encina, Francisco A. Nuestra Inferioridad Económica, Santiago de Chile, Universitaria, 1986. Después de 1911, el libro fue reeditado en 1955, 1972, 1978, 1981 y 1986.
} 
a Chile a la altura del pueblo inglés, con sus virtudes cívicas, eficiencia económica y $\operatorname{prosperidad}^{53}$.

Para dar respuesta al problema de la inferioridad económica, Encina aplicó conceptos darwinistas a la raza y al territorio, llegando a conclusiones pesimistas sobre la población chilena:

nuestra raza, en parte por herencia, en parte por el grado relativamente atrasado de su evolución $\mathrm{y}$ en parte por la detestable e inadecuada enseñanza que recibe, vigorosa en la guerra y medianamente apta en las faenas agrícolas, carece de todas las condiciones que exige la vida industrial. Nace aquí una antinomia entre los elementos físicos tan inadecuados para una vigorosa expansión agrícola, como admirablemente adecuados para la etapa industrial, y las aptitudes de la raza, apta para la agricultura e inepta para la actividad manufacturera y comercial, que se traduce en la debilidad y estagnación económica ${ }^{54}$.

Las actividades mineras no favorecían el amor por la tierra - y el nacionalismo -, pues quien con ellas se envuelve quiere siempre retornar a la ciudad. "Una nación minera está siempre más expuesta que otras a ser absorbida económicamente, a caer en la condición de factoría de civilizaciones más poderosas" ${ }^{55}$. Las características sicológicas del chileno lo hacían recusar las profesiones liberales para no comprometer su origen noble e hidalgo y eran reforzadas por la escuela que no cuidaba de la educación física. El chileno llegaba a la edad productiva con un estado físico tan lamentable que desistía de cualquier empresa, y sus

\footnotetext{
${ }^{53}$ Pensamiento de Encina. Selección y prólogo de Teresa Pereira de Correa, Santiago de Chile, Editora Nacional Gabriela Mistral Ltda, 1974, p. 83.

${ }^{54}$ Encina, Francisco A. op. cit., pp. 32-33.

${ }^{55}$ Ídem, p. 49.
} 
actividades decaían rápidamente a partir de $\operatorname{los} 45,50$ años. La ociosidad y la falta de perseverancia eran generalizadas, herencia de los españoles, cuya mezcla de sangre bérbere o afrosemita capacitaba apenas para la guerra. El problema de los chilenos era creer mucho en glorias pasadas, glorias nunca vividas. La tierra era propicia para el desarrollo, pero faltaba iniciativas no sólo de los burgueses sino de los obreros que,

\footnotetext{
a pesar de su extraordinario vigor físico, de su inteligencia y de su orgullo (...) es incapaz del trabajo regular y sostenido propio de los pueblos bien evolucionados. Puede trabajar varios días consecutivos como sólo él puede hacerlo; pero en cualquier momento abandona su labor para ir a una francachela a consumir el tiempo conjuntamente con el dinero ganado ${ }^{56}$.
}

La imitación de la cultura europea marcaba las clases altas. De Europa habían copiado los gustos desenfrenados, el consumo y el desperdicio. Más, todos estos males venían perdurando desde las propias guerras de independencia. En Chile, tal como en las demás repúblicas hispanoamericanas, el deseo de imitar a los países europeos y de nivelar-se con ellos germinó junto con la idea de independencia o, más exactamente, fue uno de los móviles de la emancipación. Además de esto, los propios europeos habían migrado hasta Chile para imponer sus leyes económicas y las actividades comerciales, fabriles y mineras. De estos, la clase alta chilena copiaba todas las costumbres y vicios, acompañada por la sociedad entera, sobre todo en Santiago. En síntesis, en Chile los factores físicos como clima, relieve, suelo, solamente permitirían una vigorosa expansión económica a un pueblo capaz de grandes iniciativas industriales, poseedor de buenos capitales. Mientras

\footnotetext{
${ }^{56}$ Ibidem, p. 86.
} 
trabajadores y empresarios chilenos no se adecuasen al estilo de los países adelantados, el país permanecería económicamente inferior. Mientras la mano de obra extranjera no suplantase los criollos como en Argentina, la inferioridad económica persistiría. La educación tendría que cumplir su papel redentor y ser el canal de cambios, transformando herencias malditas; "la educación sistemática puede completar la transformación aún imperfecta de nuestra primitiva energía militar en aptitudes industriales". Una política económica y comercial estable podría auxiliar la educación en esa pesada tarea que el destino y los propios errores habían colocado sobre los hombros de los chilenos ${ }^{57}$.

Es importante anotar que el nacionalismo de algunos de estos autores veía a los extranjeros como enemigos de la patria. Encina Armanet, por ejemplo, también protestó contra la aproximación con Argentina para solucionar el grave problema de fronteras:

.....en la clase dirigente, el pacifismo y la solidaridad americana se resolvieron en el egoismo, en el propósito de vivir el presente sin preocuparse del futuro. Pronto vamos a ver a la intelectualidad chilena y al grueso de la clase dirigente colocarse del lado de la Argentina en la disputa por la Patagonia o clamar por una transación cualquiera que evitase el peligro de la guerra, mientras la opinión argentina no sólo apoyó resultamente los derechos de su país, sino que presionó y obligó a su gobierno a no ceder en nada y aun a eludir los compromisos contraidos $^{58}$.

El crítico no percibió que acercarse a la Argentina favorecía la formación de un bloque contra la Doctrina Monroe, redefinida por los Estados Unidos como el "corolario

\footnotetext{
57 Ibidem, pp. 243-244.

58 Pensamiento de Encina, op, cit., p. 96.
} 
Roosevelt" en la disputa por territorios del continente. Los intelectuales críticos del Centenario no percibían que, posiblemente, mientras el gobierno chileno no resolviera los problemas externos de carácter fronterizo y de seguridad nacional, los problemas internos continuarían siendo solucionados por la vía de las armas, de la represí́on o de la indiferencia.

Chile del Centenario de la Independencia pasó por una profunda evaluación de su sistema político, económico y social. Intelectuales, políticos y líderes sindicales coincidían en el diagnóstico de una crisis moral generalizada cuya responsabilidad estaba en las elites dominantes y en la Iglesia Católica; pero también en su cultura heredada de la Península Ibérica, la imitación extranjera y el incentivo a la imigración.

\section{Los obreros y el nacionalismo}

Los trabajadores chilenos, en su mayoría, eran de origen nacional. Su trayectoria de luchas contra las compañías extranjeras - sobre todo en la minería - asoció la cuestión social al sentimiento nacional.

La organización obrera de Tarapacá, por ejemplo, recordaba en 1904 a una comisión parlamentaria que en el norte 'el capital en su totalidad es extranjero'. El capital foráneo, insistían, actuaba de manera sistemática con 'una política altanera y provocativa' (...) En un debate con un periodista conservador, en 1913 o 1914, en Iquique, el líder del naciente Partido Socialista atacó a los capitalistas británicos que controlaban la economía del salitre y tildó de antipatriotas a los empleados públicos corruptos que se oponían a los trabajadores. Eran los 
obreros quienes producían la riqueza de Chile y los ingresos del Estado; ellos eran los verdaderos patriotas, concluyo $^{59}$.

El nacionalismo operario se sumaba, por lo tanto, a aquel de muchos intelectuales en la época del Centenario. No se trataba de mera xenofobia: "Representan la primera voz 'nacionalista'. Reivindican los valores chilenos ante el extranjerismo desatado. Dan un grito de alarma por el hundimiento físico y moral que sufre el pueblo, el 'roto'. Merecen nuestro respeto y admiración"

Mientras Pinochet Le Brun, Palacios y Encina afirmaban que los chilenos no se preocupaban por la defensa del territorio nacional y su comercio interior, los socialistas fuertemente organizados entre los trabajadores hacían coaliciones electorales con partidos políticos cuyos programas presentaban posiciones reformistas y nacionalistas, buscando soluciones legislativas para los problemas de la clase trabajadora a nivel nacional. Apenas los anarquistas se oponían a cualquier tipo de solicitación al Estado y a la aproximación con partidos políticos ${ }^{61}$. Los trabajadores chilenos tenían puntos claros y objetivos precisos al hacer valer sus derechos desafiando a la oligarquía salitreia. Por su lado, el Estado buscaba asegurar la estabilidad de la mano de obra frente a las oscilaciones de la economía minera:

El estado chileno desempeñó un papel activo para garantizar el flujo laboral, suministrando transporte gratuito a los obreros y sus familias que salían del norte durante las severas depresiones de la industria. Y a medida que las fluctuaciones en la producción se agudizaban y la cantidad de personas implicadas aumentaba, el Estado empezó a proporcionar alimento y

\footnotetext{
59 Bergquist, Charles. Los trabajadores en la historia de América Latina, Bogotá, Siglo XXI, 1988 , p. 80.

${ }^{60}$ Vial Correa, Gonzalo, op, cit, p. 729.
} 
vivienda a los desempleados en los puertos salitreros y en la capital del país. Hacia 1913, el Estado se hallaba activamente empeñado en reclutar obreros durante los auges para reubicarlos y emplearlos durante las caídas ${ }^{62}$.

Estudiando el impacto de las migraciones en la historia de las relaciones internacionales de los países receptores, Pierre Renouvin constató que estos países se desarrollaron a nivel agrícola, como las pampas argentinas, la zona cafetera brasilera y la zona central canadiense, y que las migraciones provocaban, con la abundancia de mano de obra, los bajos salarios y el desempleo ${ }^{63}$. Ya en Chile, donde la imigración europea fue menos acentuada, el gobierno subsidió la migración interna de la mano de obra nacional, lo que ciertamente representaba algunas mejorías de carácter social y político. Los trabajadores chilenos conocían el territorio que intentaban defender de los extranjeros; migraban del sur para el norte, aprovechando el buen desarrollo de las ferrovías que ampliaban e integraban el mercado nacional. Siendo en su mayoría solteros, los operarios salitreros desarrollaron una red informal de comunicaciones entre amigos, parientes y compadres por todo el país. Seminómadas, salían de los talleres y fábricas para visitar parientes y amigos, comían carne hasta tres veces al día, participaban en funerales e iban a reuniones políticas en los puertos; en los pueblos, a lo largo de las ferrovías, bebían, jugaban, visitaban prostitutas, hacían compras y discutían sus asuntos comunes ${ }^{64}$. Esta red los ayudaba a comprender el país: además de las cuestiones de tipo laboral, también se daban cuenta de la cultura, de la

\footnotetext{
${ }^{61}$ Bergquist, Charles, op. cit., p. 88.

${ }^{62}$ Ídem, p. 56.

${ }^{63}$ Renouvin, Pierre. "Os Movimentos Migratórios", en: RENOUVIN P. \& DUROSELLE, J.B., Introdução à Historia das Relações Internacionais, Rio de Janeiro, Difusão do Livro, 1967.

${ }^{64}$ Bergquist, Charles, op. cit, pp. 70-75.
} 
geografía, imaginando el país que sabían era de ellos, que querían amar y respetar. Así, los obreros iban formándose una idea acerca del país; su lucha permitiría usufructuar un poco más de la madre patria, cuyo cuerpo geográfico lleno de recursos aseguraba alimento y relativa seguridad.

Entre la consciencia nacional de los trabajadores y el Estado había un abismo. En setiembre de 1910, un órgano de la prensa obrera, que no olvidaba la masacre reciente de Iquique, veía el Estado chileno como una madrastra cruel: “gocen los libres, los que viven en las alturas, disfrutando de las comodidades y placeres que les proporciona la Patria, que es para ellos madre amante y cariñosa, y madrastra cruel y sin entrañas para el pueblo trabajador" ${ }^{65}$. Algunos años más tarde,

el único documento preparado por una organización obrera que fue publicado en el informe de la Comisión Parlamentaria de 1913, declaraba que cinco minutos de descargas de fusilería aprobadas oficialmente en contra de los pacíficos huelguistas de Iquique en 1907, había hecho más para destruir su patriotismo y su respeto por la autoridad gubernamental que 'medio siglo de propaganda sistemática de mil anarquistas' ${ }^{166}$.

Los primeros círculos de carácter socialista, antiburgueses, que sólo admitían operarios, como el Centro Social Obrero y la Agrupación Fraternal Obrera, databan de $1896^{67}$. El Partido Socialista, fundado en 1897, comenzó rápidamente a desagregarse hasta que sus cuadros se pasaron al Partido Demócrata en 1902. Pedro Montt, candidato a la presidencia

\footnotetext{
65 José Arnero, Santiago, setembro de 1910, n 177.

${ }^{66}$ Bergquist, Charles, op. cit., p. 87.

${ }^{67}$ Vial Correa, Gonzalo, op. cit., p. 871.
} 
para el período 1906-1910 por el Partido Demócrata, prometía reformas políticas y constitucionales y mejorías de orden socioeconómico. Uno de sus seguidores fue, en esta época, el dirigente socialista Emilio Recabarren, pero la masacre en la Escuela Santa María de Iquique eliminó cualquier posibilidad de apoyo popular al gobierno de Montt. Es posible que Recabarren fuese uno de los redactores del periódico José Arnero, donde se manifestaba inconformidad frente a la adhesión de muchos obreros a la conmemoración del Centenario:

masas patrioteras que con el febril entusiasmo recorren las calles dando gritos de viva Chile (...) de todas partes brotan gritos de entusiasmo y voces de vítores a la emancipación política del Estado. Ante tamaña alegría nosotros nos preguntamos: Qué motivos tiene el pueblo para sentirse tan contento y lleno de regocijo en los días de aniversario de la república nacional? (...) no han sido y son los mismos esclavos del capital ${ }^{68}$

Por lo visto, algunos sectores de trabajadores comulgaban por lo tanto con las ideas de la elite, pero la gran mayoría entendía, a diferencia de algunos de los intelectuales citados, que los cambios se lograrían con una intensa lucha contra los patrones y presionando al gobierno para que favoreciera políticas de cuño social. Por las fuentes consultadas se entiende la forma como intelectuales de clase alta o media y líderes sindicales, así como los propios obreros, fueron delineando una identidad ligada a un fuerte nacionalismo que quería construir la verdadera chilenidad. Inclusive la prensa, de carácter burgués, como El Ferrocarril y el Diario Ilustrado, hicieron denuncias a favor de los indios conquistados finalmente en la antesala de la fiesta del Centenario. Podemos anotar que mientras las elites 
económicas y políticas se identificaban con los discursos de los intelectuales latinoamericanos que, como Rodo, resaltaban las ventajas de la "raza ibérica" y el americanismo, al interior del país, muchas voces se levantaron para identificar a Chile con lo propio, criticando a esa elite que se identificaba con lo extranjero y lo ibérico especialmente; Chile intentaba favorecer un tipo de relaciones internacionales que, predicando el americanismo, quería solucionar las pendencias fronterizas que no dejaban dormir en paz a los diplomáticos del continente.

\section{BIBLIOGRAFIA}

BARRÍA SERÓN, Jorge. "Evolución histórica de Chile de 1910 hasta nuestros días", en Anales de la Universidad de Chile, año CVVIII, n $120,1960$.

BERGQUIST, Charles. Los trabajadores en la historia de América Latina, Bogotá, Siglo XXI, 1988.

CÁCERES QUIERO, Gonzalo, DEL ALCÁZAR GARRIDO, Joan et al.. Las primeras democratizaciones en América Latina: Argentina y Chile, 1880-1930, Valencia, Tirant lo Blanch Libros, 1997.

GAZMURIR, Cristian. Testimonios de una crisis, Chile: 1900-1925, Santiago, Universitaria, 1980.

HEREDIA, Edmundo. El imperio del guano. América Latina ante la guerra de España en el Pacífico,Córdoba (Argentina), Alción Editora, 1998.

LARRAÍN IBÁÑEZ, Jorge. Modernidad, razón e identidad en América Latina, Santiago, Andrés Bello, 1996.

\footnotetext{
${ }^{68}$ José Arnero, Santiago, septiembre de 1910, No. 177.
} 
OZOUF, Mona. La fête révolutionnaire, 1789-1799, Pari, Gallimard, 1976.

RENOUVIN, Pierre, "Os Movimentos Migratórios", en RENOUVIN, P. \& DUROSELLE,

J.B., Introdução à História das Relações Internacionais, Rio de Janeiro, Difusão do Livro, 1967.

SUBERCASEAUX, Bernardo. ¿Chile, un país moderno? Santiago, Ediciones B, 1996.

SUBERCASEAUX, Bernardo. Historia de las ideas y de la cultura en Chile, Tomo II. Santiago de Chile, Universitaria, 1997.

VIAL CORREA, Gonzalo. Historia de Chile (1891-1973). Vol. I, La sociedad chilena en el cambio de siglo (1891-1920), Santiago de Chile, Santillana, 1981.

ZEA, Leopoldo. América Latina: largo viaje hacia si misma, Caracas, Universidad Central de Venezuela, 1983.

BELLO, Joaquin Edwars. El Roto, Santiago, Editorial Universitaria, 1998.

CANGE, J. Valdes. Sinceridad, Chile Íntimo en 1910, Santiago, Universitaria, 1910.

Centenario Chileno. Discurso pronunciado por el Ministro de Relaciones Exteriores de la República Argentina Dr. Carlos Rodríguez Larreta en la colocación de la primera piedra del Monumento a la Independencia de Chile, 18 de septiembre de 1910, Santiago de Chile, Imprenta Barcelona, 1910.

ENCINA, Francisco A., Nuestra Inferioridad Económica, Santiago, Universitaria, 1986. Después de 1911, el libro fue reeditado en 1955, 1972, 1978, 1981 y 1986.

JOBET, Julio César, BARRÍA, Jorge et al.. Obras Selectas de Luis Emilio Recabarren, Santiago de Chile, Quimantú, 1971.

MACIA, Salvador. "El Dogma de la Paz Americana", Paraná, Coronado, 1910, 14 pp. 
MACIA, Salvador. "Una impresión de viajero", Buenos Aires, Imprenta La Leonesa, 1910.

MAC-IVER, Enrique. Discurso sobre la crisis moral de la República, Santiago, Moderna, 1900.

MARTÍ, José. Nuestra América, Barcelona, Ariel, 1970.

PALÁCIOS, Nicolás. Raza Chilena, tomo I. Santiago, Chilena, 1918.

Pensamiento de Encina. Selección y prólogo de Teresa Pereira de Correa, Santiago de Chile, Editora Nacional Gabriela Mistral Ltda, 1974.

PINOCHET LE BRUN, Tancredo. La Conquista de Chile en el siglo XX, Santiago de Chile, La Ilustración, 1909.

RODO, José Enrique. El Centenario en Chile. Discurso pronunciado, en representación del Uruguay, en la sesión solemne celebrada por el congreso chileno, durante las fiestas del Centenario, el 17 de Setiembre de 1910, Montevideo, Impresora Uruguaya Colombino S.A., 1975.

SARMIENTO, Domingo Faustino. Facundo, Buenos Aires, Centro Editor de América Latina \& Biblioteca Argentina Fundamental, 1979.

\section{Prensa:}

EI Diario Ilustrado, Santiago, 18/09/1910.

El Ferrocarril, Santiago, 07/11/1909.

El Mercurio, Santiago, 18/09/1910.

El Mercurio, Santiago, 19/09/1910.

José Arnero, Santiago, septiembre de 1910, nº 177.' 
